\title{
EL VIAJE A GRANADA DE UN TROVADOR ALEMÁN DEL SIGLO XV: OSWALD VON WOLKENSTEIN
}

\author{
Pino VALERO-CUADRA \\ Universidad de Bielefeld (Alemania)
}

\section{1.- INTRODUCCIÓN}

En 1865, el crítico alemán Adolf Friedrich von Schack, al hablar en su libro Poesía y arte de los árabes en Espanta y Sicilia ${ }^{1}$ sobre las relaciones entre granadinos y castellanos en tiempos de paz, afirmaba que la existencia de dichas relaciones se veían reflejadas en las probadas visitas realizadas por caballeros cristianos a la corte nazarín. En ese contexto, von Schack hacía referencia a la figura del caballero, músico y trovador tardío alemán Oswald von Wolkenstein (ca. 1367-1445), el cual habría sido recibido, en uno de sus múltiples viajes, por el rey moro de Granada en su corte:

"(..) no sólo durante las guerras entre fronterizos notamos que hay relaciones entre castellanos y granadinos, sino que también en tiempo de paz fue visitada la corte de los nazaritas por caballeros cristianos, de los cuales, unos buscaban alli un asilo contra las persecuciones, $y$ otros iban por mera

${ }^{1}$ von Schack, Adolf Friedrich, Poesie und Kunst der Araber in Spanien und Sicilien, I, Berlin, 1865. Hemos utilizado la traducción de Juan Valera: Poesía y arte de los árabes en España y Sicilia, Sevilla, 1881 (reimpreso en Madrid en 1988). Sobre los diversos problemas de traducción e interpretación que esta versión al castellano ha provocado véase la extensa reseña a este libro hecha por Francisco Caravaca en: Boletín de la Biblioteca de Menéndez Pelayo, 46 (1970), pp. 207-259.

2 von Schack, p. 284. 
curiosidad, a lo que parece. Ejemplo de estos últimos fue el caballero y poeta Oswaldo de Wolkenstein, el cual estuvo en Granada, en el año de 1412, en la corte del rey Bermejo. Alli fue recibido muy benévolamente el caballero Oswaldo, quien después se jactaba de que habia aprendido la lengua arabiga"3

En una nota a pie de página, von Schack aporta cuatro versos, dos de un poema de Wolkenstein en el que éste asegura hablar francés, catalán, castellano y "moro", así como otros dos de un segundo poema, bastante tardfo dentro de su producción poética, en el que se encontraría la declaración de su estancia en la corte del rey Bermejo ${ }^{4}$. Junto a ello, el crítico alemán recoge un párrafo extraído de la primera biografía que se hizo sobre este trovador, la escrita en $1850^{5}$ por Beda Weber, contemporáneo de von Schack, y en la que aparece narrada esa visita a la corte nazarí de la siguiente manera:

"Oswaldo fue muy benévolamente recibido por el rey Bermejo. Grandes honores y costosos presentes recompensaron su arte y talento para cantar. Las damas se sintieron entusiasmadas por el cantor tirolés. Y, en efecto, no podía imaginarse más interesante contraposición que los cantares tiroleses de Oswaldo cantados por su voz varonil, y los romances arábigos llenos de indecible ternura y entonados por las bellas moriscas. Apenas se pasaba una tarde en que no hubiese tales conciertos. Oswaldo permaneció por allí largo tiempo estudiando bien las costumbres de los moros e imitando su modo de ser. Cuando volvió a Alemania, cantaba romances moriscos para divertir a su auditorio y hacía con gran propiedad el papel de un caudillo árabe ..."6

El evidente exotismo del pasaje y el tono "romántico" que éste rezuma contrastan, sin embargo, en nuestra opinión, con el verdadero sentido con el que el poeta hablaba de sus viajes por el mundo, y, más concretamente, a España y Granada, en sus poemas. Por eso, el objeto de este trabajo no es sino aclarar el sentido de las "Reiselieder", o

${ }^{3}$ von Schack, pp. 284-285.

${ }^{4}$ von Schack, op. cit., pp. 285 , nota 1.

${ }^{5}$ Weber, Beda, Oswald von Wolkenstein und Friedrich mit der leeren Tasche, Innsbruck, 1850 .

${ }^{6}$ von Schack, p. 285 , que a su vez cita de Weber, op.cit., p. 181. 
poesras de viaje del músico alemán, dentro del contexto de su oficio de caballero de principios del siglo $\mathrm{XV}$, y exponer el papel que tuvo el primer editor de sus poemas y biógrafo, el citado Beda Weber, en la creación de un mito romántico en torno a la figura de Oswald von Wolkenstein, definido tradicionalmente por la crítica alemana como "el último trovador alemán" ${ }^{17}$ también unánimemente considerada por ésta como un viajero y aventurero excepcional ${ }^{8}$.

\section{2.- EL MITO ROMÁNTICO DE LA FIGURA DE OSWALD VON WOLKENSTEIN.}

Tras el interés por el estudio de la figura de Wolkenstein que la edición de 1847 y la posterior biograffa de Beda Weber en 1850 provocaron entre sus contemporáneos y otros críticos del siglo XIX, a Io largo del siglo XX, y sobre todo a partir de 1960, se han sucedido los intentos por poner en su lugar la verdadera dimensión historica y poética de este trovador, así como por desterrar la errónea valoración de su figura que se derivó de la edición y biografia de Weber y que consiste en el hecho de que ha sido considerado frecuentemente más como un personaje romántico que como el músico y poeta de fines de la Edad Media que fue.

Asŕ, en 1904 apareció la edición de la obra poética de Wolkenstein realizada por Josef Schatz, la cual intentaba corregir algunas interpretaciones erróneas de la edición de Weber ${ }^{9}$. Años más tarde, en 1961, el crítico Norbert Mayr, autor de un excelente estudio sobre los viajes y canciones de viaje de Wolkenstein ${ }^{10}$, explicaba que el mayor problema que se derivaría de la biografia de Beda Weber es el hecho de que éste

${ }^{7}$ Wehrli, Max, Geschichte der deutschen Literatur von den Anfängen bis zur Gegenwart, Tomo I, Stuttgart, 1984, p. 747.

${ }^{8} \mathrm{Cf}$. Golther, Wolfgang, Die deutsche Dichtung im Mittelalter. 800 bis 1500 , Stuttgart, 1912, pp. 465-468 y Wehrli, op. cit., pp. 747-753.

${ }^{9}$ Cf. Schatz, Josef, Die Gedichte Oswalds von Wolkenstein, Göttingen, 1904.

${ }^{10}$ Mayr, Norbert, Die Reiselieder und Reisen Oswalds von Wolkenstein, Universitätsverlag Wagner, Innsbruck, 1961. 
utilizó para escribirla una notas de viaje, las llamadas "Reisenotate", supuestamente escritas por el poeta al margen de los manuscritos de sus poesías y actualmente desconocidas. Mayr cree que dichas notas fueron escritas por otra persona tras la muerte del poeta, seguramente por su hermano, y recreadas posteriormente por Beda Weber ${ }^{11}$. Un año después, en 1962, Kurt Klein publicó una nueva edición en alemán antiguo de los poemas de Wolkenstein en cuyo prólogo el autor hace un breve repaso a los errores y problemas que la edición y biografia de Beda Weber provocaron en su consideración de este autor como una figura mítico-romántica ${ }^{12}$. Varios años después, en 1977, A. Robertshaw, expresaba de esta forma el papel de Beda Weber en la "creación" de un mito histórico y literario en torno a la figura de Oswald von Wolkenstein en la introducción a su libro Oswald von Wolkenstein: the myth and the man:

"...Weber created what Kurt Klein called 'einen Oswald-Mythus', compounded of historical inaccuracies and a romanticized picture of the poet's personality. The aim of the present study is to contribute to the correction of the "mythical" image of Oswald"13.

Más recientemente, en 1986, Karen Baasch y Helmuth Nürnberg han criticado el hecho de que Weber iniciase la edición de sus poemas precisamente con la poesía titulada "Durch Barbarei, Arabia", en un intento de hiperbolizar el carácter aventurero de Wolkenstein y decantar éste hacia el exotismo oriental que tanto ha contribuido a deformar la visión que se ha tenido sobre este poeta ${ }^{14}$ :

${ }^{11}$ Cf. Mayr, op. cit., pp. 15-30. A pesar de sus críticas a Weber, Mayr cree, por las referencias que Wolkenstein hace en sus poemas, que el viaje y la visita a la corte granadina fueron reales ( $C f$. op. cit., pp. 70 y ss).

${ }^{12}$ Cf. Klein, Kurt, Die Lieder Oswalds von Wolkenstein, Tübingen, 1962, pp. VII-XVIII.

13 A. Robertshaw, Oswald von Wolkenstein, the myth and the man, Göppingen, 1977, p.1. Aunque, como recogemos en esta cita, pretenda corregir la imagen mítica romantizada de Wolkenstein, también este crítico, siguiendo a Mayr, considera cierta la visita del trovador a la corte del Rey Rojo (Cf. op. cit., p. 23).

14 Cf. Baasch, Karen y Nürnberg, Helmuth, Oswald von Wolkenstein, 


\begin{abstract}
"Beda Weber, el primer editor y biógrafo, colocó esta canción, que en conjunto se compone de siete estrofas, al comienzo de su edición, de manera que este texto juega un importante papel en todas las reflexiones sobre la biografía de Oswald. La vieja crítica completaba con fantasía las escasas pero contundentes afirmaciones [del poeta] para poder realizar una exhaustiva descripción de los años de juventud, de los cuales apenas existe documentación" ${ }^{15}$.
\end{abstract}

Podemos afirmar, pues, después de haber hecho este breve recorrido por algunos de los autores que han contribuido a la "corrección" del mito sobre la figura de Wolkenstein, que la biografía de Weber que provocó la creación del mismo no respondía precisamente a lo que se llama "fidelidad a la verdad histórica", y su afán "romantizador" sería, pues, la explicación de la exótica descripción de la visita a la corte nazarí en Granada contenida en esta biografía citada por von Schack con la que iniciábamos este artículo, y responsable de la aureola mítica general que rodea al músico y poeta tirolés.

Desde un punto de vista estrictamente histórico, Oswald von Wolkenstein, nacido hacia 1367 en el seno de una importante familia aristocrática tirolesa y que se marchó de casa a los diez años como escudero de un caballero, fue, efectivamente, un gran viajero, pero es ésta una actividad que debe vincularse, además de a su oficio de caballero medieval, a la destacada labor diplomática que realizo $\sigma^{16}$. Por lo que se refiere al tema de su viaje a Granada y su visita a la corte en 1412 , tal y como recogía von Schack, es de destacar que, en ninguna de las breves biografias que aparecen en las historias generales de la literatura alemana que hemos consultado, aparece referencia alguna a este viaje, un viaje que, en realidad, nunca hasta ahora ha podido ser documentado. Lo único que parece estar probado históricamente, según Robertshaw, es el viaje que, en el marco de su embajada durante el Concilio de Konstanz, hizo Oswald, en 1415 (y no en 1412, como afirmaba von Schack) ${ }^{17}$, a España (¿desde Inglaterra y Portugal?), y

Rowohlt Taschenbuch Verlag GmbH, Reinbek bei Hamburg, 1986, pp. 9-17.

${ }^{15}$ Baasch y Nürnberg, op. cit., pp. 10-11 (la traducción es mía).

${ }^{16} C f$. la cronología de Robertshaw, en op.cit., pp. vi-viii.

${ }^{17}$ La problemática en torno a la fecha del viaje de Wolkenstein a España ha 
más concretamente a Aragón, y su posterior viaje a Perpiñán, en Francia, donde lo encontramos en $1416^{18}$.

La reconstrucción del viaje a Granada se ha venido haciendo tradicionalmente a partir de dos poemas: "Durch Barbarei, Arabia" y, sobre todo, "Durch Abenteuer, Berg und Tal" ${ }^{19}$. En el primero se describe como algo real, en pasado, un viaje desde Irlanda e Inglaterra a Portugal, desde donde se habría dirigido a Aragón -estancia que es la que pudo haber aprovechado para visitar Granada-, y de ahi, a Francia. En el segundo, junto a la descripción del mismo recorrido y el añadido de su participación en la conquista de Ceuta, se menciona el deseo de Wolkenstein de ser recibido por el "Rey Rojo" nazarí Yūsuf III en su corte de Granada ${ }^{20}$. Dicha visita, que, como el viaje a Granada, no ha

sido explicada por Mathias Feldges en: "In Katlon und Ispanien, do man gern ist kestanien", Zeitschrift für deutsche Philologie, 95 (1976), pp. 378-379, nota 23. M. Feldges explica que la fecha del viaje a España fue fijada por Beda Weber en su biografía basándose en las "Reisenotate" o "notas de viajes" supuestamente escritas por Oswald a las que hacíamos referencia antes, $y$, especialmente, en la que menciona su participación en la conquista de Ceuta hecha por los portugueses en el verano del año 1415 y que en las perdidas notas se establece erróneamente en el verano de 1411 sin que Weber se diese cuenta del error. Quien sí lo advirtió fue A. Noggler ("Eine unbekannte Reise Oswalds von Wolkenstein", en: Zeitschrift des Ferdinandeums, 27 [1883], pp. 5-61), el cual, en vez de, simplemente, corregir la fecha, se inventó un segundo viaje a España de Wolkenstein en 1415. El primero que lo aclaró fue N. Mayr, quien, sin embargo, como ya hemos indicado en la nota 11 , a pesar de la falta de documentos que lo prueben, cree en la existencia del viaje de Wolkenstein a Granada. Esta opinión es seguida también, a partir de los estudios de Mayr, por U. Müller (Dichtung und Wahrheit in den Liedern Oswalds von Wolkenstein, Göppingen, 1968), quien afirma que el viaje que aparece como planeado en uno de sus poemas (el número 26 según la edición de $\mathrm{K}$. Klein y que veremos enseguida), no sería sino una proyección del verdaderamente realizado en 1415. También afirma que, en 1423, cuando compuso el citado poema, en fecha tan tardía, no podía estar planeando ya ningún viaje, y que eso confirma que son sólo recuerdos del viaje anteriormente realizado. Creemos que el error de esta argumentación reside en el hecho de que la utilización de recuerdos de viaje con fines poéticos no demuestra que un viaje haya sido históricamente cierto.

${ }^{18}$ Cf. A. Robertshaw, op.cit., p. vi.

${ }^{19}$ Seguimos la edición de K. Klein citada en la nota 12 y, a partir de ahora, damos su numeración entre paréntesis.

${ }^{20}$ Ha sido N. Mayr el que ha identificado al rey Bermejo del poema con 
podido ser demostrada hasta ahora documentalmente, aparece descrita únicamente en este poema y, además, es narrada como algo hipotético, planeado y, por tanto, en principio, no realizado. Por eso, pasamos a analizar ahora la dimensión literaria de nuestro autor y a mostrar las poesías en las que el poeta hace referencia a España y sus distintos reinos $^{21}$, asi como el que describe la mencionada visita a la corte nazarí en Granada, para intentar interpretar sus referencias a esta supuesta visita a la corte granadina en 1415 .

\section{3. - LA DIMENSIÓN LITERARIA DE LOS VIAJES DE OSWALD VON WOLKENSTEIN.}

El aspecto más importante que hay que tener en cuenta a la hora de considerar el problema que nos ocupa es el del significado que la literatura de viajes tenía entonces, a finales del siglo XV y, sobre todo, el hecho de que haya sido escrita por un caballero, por alguien que se considera y se define a sí mismo como un caballero y que, por tanto, escribía dentro de los cánones de la literatura caballeresca, lo que quiere decir que Wolkenstein asumía al escribir las convenciones que su oficio conllevaba en cuanto a actitudes vitales y literarias. Dichas actitudes pueden ser resumidas en tres aspectos esenciales:

a) El amor de tipo cortés trovadoresco, que se caracteriza por la devoción hacia una dama y la imposibilidad de culminar su deseo por ella.

Yūsuf III. Cf. N. Mayr, op. cit., p. 50.

${ }^{21}$ Mathias Feldges, en el artículo citado en la nota 17, se pregunta por qué Wolkenstein menciona España junto a los distintos reinos de la península en una época en la que España aún no había sido constituida como un país moderno unificado. Tras analizar las distintas poesias en las que el trovador menciona España y sus distintos reinos, concluye que en los poemas de Wolkenstein el término "España" es utilizado, o bien para referirse al antiguo reino de GaliciaLeón, nunca mencionado en los mismos, o bien para denominar a la Península Ibérica en general, con excepción de Portugal y Granada (Cf. op. cit., p. 399). 
b) La defensa de la cristiandad que da origen a la caballería durante las cruzadas medievales iniciadas en el siglo XII.

c) El sentido de la aventura y el riesgo como algo inherente a la vida del caballero.

Los dos primeros aspectos los encontramos en varios de sus poemas pero no vamos a entrar aquí en su consideración por no ser el objeto de este trabajo. El tercer aspecto, el de los viajes y el sentido aventurero, es el que nos lleva directamente al problema del viaje a Granada y de la visita a la corte supuestamente realizada por el trovador alemán. Como dice Norbert Mayr, "injustamente se califican los viajes de Oswald como algo único", puesto que simplemente "el caballero es, por naturaleza, un viajero" ${ }^{122}, y$, por tanto, el sentido que tendrían las constantes referencias a los distintos países visitados no sería otro que reforzar y dar más consistencia y credibilidad a su condición de caballero con todo lo que eso lleva consigo en cuanto a convenciones literarias, $y$, sobre todo, independientemente de que hubiese llevado a cabo o no esos viajes.

Según Norbert Mayr, desde los primeros caballeros medievales, representados literariamente en figuras como Percival, hasta Wolkenstein, lo que habría cambiado serf́a el significado que los viajes tenían para estos personajes. Así, para los caballeros medievales, los viajes y la lejanía del entorno habitual constitúan una obligación y una dura realidad que, por tanto, no se consideraba susceptible de ser idealizada, mientras que para los autores más tardíos, como Wolkenstein, sería más una convención literaria, y de ahí la necesidad de presentarlos como algo heroico y excepcional. En ambos casos, los viajes y la aventura son algo consustancial a su vida caballeresca, pero es cuando esa vida ha perdido su función cuando el riesgo se convierte en algo digno de ser poetizado -evolución que el citado crítico ejemplifica desde autores alemanes del siglo XIII hasta contemporáneos de nuestro poeta ${ }^{23}-$, de

${ }^{22}$ Cf. N. Mayr, op.cit., p. 9 (la traducción es mía). Recuérdese que, a pesar de sus críticas a la biografía de Beda Weber, este autor considera dicha visita históricamente real.

${ }^{23}$ Cf. N. Mayr, op.cit., pp. 10-15. 
la misma manera que cuando un género literario se convencionaliza pasa también a responder más a tópicos que a realidades. Por eso creemos que, aunque muchos de los lugares nombrados por Wolkenstein no hayan sido nunca visitados por él, se puede decir que el caballero Oswaldo utilizo sus viajes como diplomático -y otros nunca realizadospara reconvertirlos en recuerdos de viaje de un caballero por el mundo, es decir, como un topos literario, un topos que era, por otra parte, frecuente en la literatura de viajes de la época ${ }^{24}$. Ese sería el sentido de las referencias a España y a sus distintos reinos en sus poemas ${ }^{25}$.

Las canciones en las que aparecen dichas referencias, aparte de las citadas "Durch Barbarei, Arabia" (Kl.44) y "Durch Abenteuer, Berg und Tal" (KI. 26), que han sido utilizadas para reconstruir el supuesto viaje a Granada y que veremos más tarde con más detalle, son las siguientes: "In Frankreich" (K1. 12), "Es fügt sich" (Kl. 18), "Es ist ein altgesprochener Rat" (Kl. 19), "Es fließt dort der von Orient" (Kl. 20), "Wie will ich singen und dichten" (Kl.23).

En todos estos poemas, España o sus distintos reinos aparecen citados siempre en las largas enumeraciones de paises con las que Oswald suele comenzar sus poemas, como en el número 12 , en el que, tras una de esas enumeraciones de los lugares visitados, Wolkenstein afirma haber visitado y viajado por todos esos reinos:

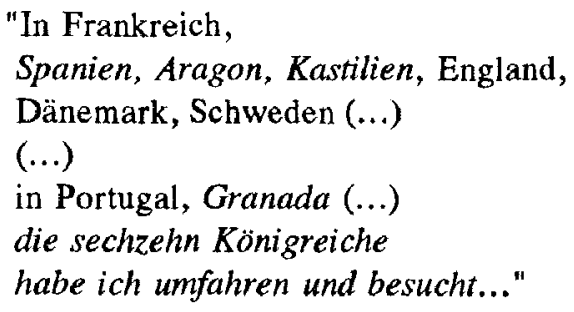

${ }^{24} C f$. M. Feldges, op. cit., pp. 380-381.

${ }^{25} \mathrm{Cf}$. sobre la presencia de la lengua española en las poesías de Oswald von Wolkenstein el artículo de Leo Spitzer, "Romanisches bei Oswald von Wolkenstein", en: Neuphilologische Mitteilungen, 21 (1920), pp. 74-77, en donde destaca la presencia de aragonesismos en algunos versos, seguramente aprendidos durante su estancia en Aragón en 1415. 
A continuación, nos cuenta sus hazañas amorosas con una bella mujer y con las reinas de los lugares visitados, lo cual cuadraría con la imagen que se debe tener de un caballero y trovador.

Del mismo tipo es el poema número 18, en el que también hace una larga enumeración de países visitados y de los idiomas aprendidos -un total de diez, entre ellos, el "moro"- para, a renglón seguido, contar sus amores con la reina de Aragón, a la que podría haber conocido durante su visita a este reino en 1415 :

"Nach Preußen, Lituanien, Tartarei, Türkei übers Meer nach Frankreich (..) Spanien (...)

(...) französisch, maurisch, katalanisch und kastilisch deutsch, lateinisch (...) die zehn Sprachen habe ich gebraucht $(. .)^{m 26}$

En el número 19 destaca la referencia a España y Cataluña y al hecho de que la gente alli guste de comer castañas:

$$
\begin{aligned}
& \text { "(...) in Katalonien und Spanien } \\
& \text { wo man gern ißt Kastanien }{ }^{27} \text {. }
\end{aligned}
$$

En el poema número 23 hace alusión a sus necesidades de viajar al extranjero y vuelve a nombrar a Granada:

${ }^{26}$ Ésta es la referencia que aducía von Schack a la que aludíamos al principio de este trabajo. Sobre el multilingüismo en la literatura de la época $c f$. Walter Rüll, Oswald von Wolkenstein, Darmstadt, 1981, pp. 88-90. En su opinión, el multilingüismo del que presume Wolkenstein en sus poemas tendría, al igual que las largas enumeraciones de países, un valor estético, y no comunicativo. La lengua árabe aparece mencionada en sus poemas porque también aparece citada Berbería, por ejemplo. Por eso, no habría que considerar como cierta la afirmación del poeta de que hablaba el árabe ni aducir ésta como una prueba de que su visita a la corte nazarí fue real. Además, no tendria por qué haber aprendido esa lengua necesariamente a lo largo de esa visita -como insinúa von Schack al citar juntos los versos en los que el poeta afirma hablar "moro" y los que relatan la visita a la corte nazari-sino, quizás, en uno de sus viajes a países de habla árabe.

${ }^{27}$ Cf. a propósito de este poema el artículo de Mathias Feldges citado en la nota 17. 


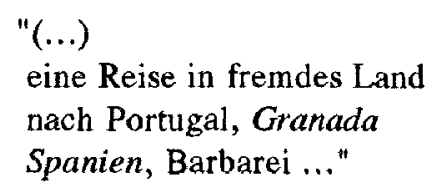

En cuanto al número 27 , solamente indicar que vuelve a mencionar a Cataluña.

En el famoso poema "Durch Barbarei, Arabia" (KI. 44), uno de los que ha servido para dar por cierto el viaje de Oswald a Granada y con el que, como indicábamos arriba, inició Weber la edición de los poemas del trovador y que habría dado lugar a una exótica visión sobre su poesía y su vida, hace una relación de los países más remotos por él visitados a lo largo de sus numerosos viajes por el mundo. En él es en el que se describe el viaje a España y Francia desde Portugal e Inglaterra, que aún no ha podido ser documentado históricamente y que ha sido reconstruido a partir de este poema y del número 26 , que veremos enseguida con más detalle:

"Durch Berberland, Arabien,
durch Armenien nach Persien,
durch Tartarenland nach Syrien
durch Rumänien in die Türkei
nach Georgien
die Sprünge habe ich vergessen.

Durch Preußen, Rußland, Eiffenland, nach Litauen, Livland, über die Nehrung, nach Dänemark, Schweden, nach Brabant, durch Flandern, Frankreich, England und Schottland

habe ich lang nicht gemessen.

Durch Aragonien, Kastilien, Granada und Navarra von Portugal, Spanien bis nach Finisterren von der Provençe nach Marseille...."28

${ }^{28}$ Para la versión de este poema en alemán moderno nos hemos servido de 
En este poema, la enumeración de países no difiere, en realidad, de la hecha en otros poemas con excepción de la mayor longitud de ésta, pero ha sido utilizada para confirmar la existencia del viaje a Granada por el hecho de que aparezcan juntos los países por los que se ha supuesto que pasó Wolkenstein en 1415 desde Inglaterra hasta llegar a Perpiñán en 1416 (Escocia, Portugal, Aragón y Francia) y porque aparece narrado, a través de la utilización del pasado, como cierto. Como veremos en seguida, no sucede lo mismo en el siguiente, el número 26, aunque sea en el que se haya basado a veces la crítica para dar por efectivamente realizada esta visita. Por lo demás, como en el resto de los poemas citados, hay constantes referencias a amores, cautiverios, luchas, aventuras y también a su rey, el rey Segismundo, a cuyas ordenes estuvo Wolkenstein, y que representa en la vida y en la dimensión poética de Wolkenstein al señor que todo caballero-vasallo debe tener.

Así, pues, como hemos visto, en varios de los poemas de nuestro Oswaldo aparecen referencias a Granada que permitirían suponer que el trovador estuvo efectivamente alli. Creemos, sin embargo, que esta es una cuestión que sólo un documento histórico puede resolver y el objeto de este breve trabajo es únicamente demostrar que no es posible concluir que fuese un viaje efectivamentemente realizado $y$, sobre todo, que el trovador haya sido recibido por el rey nazarí a partir del único poema en el que describe con más detalle dicha visita, el número $26, \mathrm{y}$ cuyas primeras dos estrofas reproducimos en nuestra versión modernizada:

la selección de poesía de Oswald von Wolkenstein hecha por Burghart Wachinger, Oswald von Wolkenstein. Eine Auswahl aus seinen Liedern, Ebenhausen bei München, 1964, de la que sólo hemos tomado la relación de países citados. Diferimos únicamente de la identificación que este autor hace entre Finisterre y Gibraltar, sin ningún tipo de justificación, en las notas finales de sus edición, al comentar este poema (op. cit., p. 121). Por lo que se refiere a la traducción del resto de los versos (así como de los otros poemas citados, de los que no hemos podido acceder a una traducción moderna), mi más afectuoso agradecimiento por sus valiosos consejos a mi compañera de la Universidad de Bielefeld Traudl Strohm-Katzer y a su padre, que tanto me han ayudado a descifrar el significado de estos versos. 
"Durch Abenteuer, Berg und Tal, so wollte ich fahren, daß ich nicht verläge.

$A b$ nach dem Rhein hin nach Heidelberg, in England stand mir der Sinn nicht träge.

Nach Schottland, Irland über die See,

auf Handelsschiffen nach Portugal zu segeln, nach einem Blümlein war mir weh, ob ich die Liebe da möchte ersteigen von einer edlen Königin, und in meine Gewalt verriegeln.

Von Lissabon in die Barbarei, nach Ceuta, das ich damals half zu erobern, wo mancher so stolze freie Maure, von seinem Erbland mußte von hinten heraus fliehen.

In Granada hätte ich gern versucht, wie mich der Rote König noch hätte empfangen können, zur Ritterschaft war ich bestimmt, vor meinen Kindern, wäre ich dahin gegangen; dafür müßte ich zu Tisch als ein Stubenhocker prahlen."

La traducción del texto sería la siguiente:

"A través de aventuras, montañas y valles, así quería yo viajar, para no anquilosarme ${ }^{29}$. Desde el Rin río abajo hacia Heidelberg, en Inglaterra nunca me faltó el ánimo para, hacia Escocia, hacia Irlanda, sobre el mar, navegar en barcos mercantes hacia Portugal, con dolorosa añoranza de una florecilla, con el deseo de cabalgar allí el amor de una noble reina, encerrarlo en mi violencia.

${ }^{29}$ El verbo alemán verliegen significa "anquilosarse" en el sentido de que los huesos y el cuerpo en general se entumecen por la falta de movimiento. Aquí hemos utilizado el verbo "anquilosarse" por su mayor sonoridad y porque lleva consigo una connotación de entumecimiento también espiritual. 


\begin{abstract}
Desde Lisboa hacia Berberia, a Ceuta, la cual entonces ayudé a conquistar, donde algún orgulloso moro libre, tuvo que huir por la retaguardia de su patria natural. Mucho hubiera deseado en Granada intentar, que el Rey Rojo me hubiera recibido, fui determinado para la caballería, delante de mis hijos, hubiera ido alli; en vez de eso tendría que haberme jactado de sentarme en la mesa como un trashoguero ${ }^{30}$."
\end{abstract}

En la primera estrofa aparecen claramente utilizados dos de los motivos literarios inherentes a la vida del caballero: los viajes y la aventura, y el fogoso deseo por una noble dama, lo cual nos confirma la necesidad de interpretar sus poemas no como algo real sino como literatura trovadoresca. La segunda estrofa es, por el contrario, mucho más difícil de comprender. Parafraseándolo, Wolkenstein nos dice, utilizando inequívocamente el condicional, es decir, un tiempo verbal irreal, que le hubiera gustado ser recibido por el rey nazari en Granada. Asimismo explica que habra nacido para ser un caballero y que, -creemos que ésta sería la correcta lectura de los tres últimos versos de la segunda estrofa- si hubiera ido a la corte, hubiera tenido que explicarles más tarde a sus hijos que se habra comportado como alguien que nunca se mueve y lleva una vida sedentaria, es decir, que había caído en el anquilosamiento que -como explica al comienzo del

${ }^{30}$ trashoguero: "persona casera y sedentaria". Por lo que se refiere a la puntuación del poema, hemos respetado, puesto que no pretendemos hacer aquí una edición crítica del mismo, la dada por K. Klein en su edición citada en la nota 12. El único problema que nos plantea la misma es el punto y coma antes de los dos últimos versos de la segunda estrofa, los más difíciles de interpretar, que quedarían así separados de los anteriores. Teniendo en cuenta que esos dos versos se encuentran en la misma estrofa que aquéllos, que concuerdan asimismo en el uso del condicional con ellos y que, además, a finales del siglo XV las reglas de los signos de puntuación no estaban fijadas como en la actualidad, consideraríamos conveniente colocar ahi una coma, lo que permitiría, como hemos hecho, interpretarlos con el conjunto de la estrofa. Sin embargo, como no conocemos el manuscrito original y no hemos podido acceder a ninguna otra edición, respetamos, como hemos indicado, la puntuación dada por $\mathrm{K}$. Klein, pero nos ratificamos en nuestra interpretación. 
poema- quería evitar a toda costa, por ser totalmente contrario al ideal de vida caballeresco.

Así, pues, queda claro que la visita a la corte nazarí en Granada, según estos versos, fue hipotética y no llevada a cabo, como nos indica claramente el uso verbal del condicional, algo que, demasiado frecuentemente, los críticos han preferido ignorar. La explicación de Müller (véase nota 17), según la cual el uso irreal del verbo en un poema tan tardío sólo puede responder a la reconstrucción de un viaje anterior, el realizado en 1415, demostraría el uso de los viajes con fines poéticos que, tal y como explica Mayr, caracterizarfa a los trovadores tardíos, pero nunca puede confirmar la existencia histórica de una visita que hasta ahora ningún documento ha podido avalar. En cambio, si únicamente buscamos en el poema las palabras de un caballero, entonces la problemática cambia totalmente, encontrándose la clave, como ya hemos visto, en el verso "fui determinado para la caballeria". Esta afirmación no sería más que la justificación hecha por un caballero para no ir a la corte granadina, pues ello hubiera llevado consigo un comportamiento contrario a las normas de la vida caballeresca, que lleva implícita en sí el viaje y la aventura y no la vida sedentaria y el anquilosamiento físico y espiritual ${ }^{31}$. Por lo que se refiere al viaje a

31 Anton Schwob, en su artículo "Historische Realität und literarische Umsetzung. Beobachtung zur Stilisierung der Gefangenschaft in den Liedern Oswalds von Wolkenstein", en: Innsbrucker Beiträge zur Kulturwissenschaft, 9 (1979), pp. 161-234, interpreta el verso en el contexto del resto del poema y sin referirse a la problemática de la planeada visita a la corte granadina. En su opinión, estas dos primeras estrofas, que hacen un repaso a su vida de viajero, contrastarían con el resto del poema, en el que se narra su prisión durante los años 20 en Wasserburg, y que, por tanto, sería un poema sobre el sufrimiento. Según Schwob, los últimos versos de la estrofa, donde explica que se ve a sí mismo como un ser sedentario, lo que no cuadraría con su condición de caballero, se referirían a su estancia posterior en la cárcel y no a su hipotética estancia en la corte granadina. También para Otto Mann ("Oswald von Wolkenstein und die Fremde", en: Beiträge zur neueren Literaturgeschichte, 16 [1930], pp. 49-51), estas estrofas son incomprensibles para la fecha en la que se escribió el poema y en el contexto del resto del mismo. Nosotros creemos, sin embargo, tal y como hemos apuntado en la nota 30 a propósito de la puntuación, que el hecho de que aparezcan en la misma estrofa donde se narra la posibilidad que habria tenido de hacer esta visita, y que asimismo diga que tenaría que haberse sentado, expresándolo también como algo irreal, relaciona estos versos -a pesar de la 
Granada en sí, los versos no permiten excluir esta posibilidad en absoluto -si estuvo alli, no permaneció de todas formas mucho tiempo, puesto que sabemos que poco después de su estancia en Aragón se encontraba en Perpiñán-, pero tampoco permiten confirmar que dicho viaje haya sido real ni querrían decir que el poeta había aprendido alli la lengua árabe. Insistimos, además, en que la mención de Granada y otros muchos lugares así como de diversas lenguas, tiene en los poemas de Wolkenstein una función fundamentalmente poética.

Por lo tanto, podemos afirmar, tras la lectura de las estrofas anteriores, que el carácter real o no real de su visita a la corte granadina -el viaje a Granada en sí es, como hemos visto, una cuestión distinta-, sería, en primer lugar, algo imposible de deducir a partir de los versos analizados, puesto que los hechos están expresados como algo hipotético. En segundo lugar, consideramos que ese aspecto es, en realidad, irrelevante para la interpretación de los mismos. En nuestra opinión, y como ya indicábamos antes, el trovador alemán se sirve de elementos de su vida, ya sean reales o no, para escribir unos poemas que respondiesen a los tópicos caballerescos medievales del amor trovadoresco, la aventura y la defensa de la Cristiandad (de ahí seguramente que considerase que debía ser recibido por el rey nazarí). Sin olvidar hacer hincapié en el hecho de que este poema fue escrito en 1423, cuando para el trovador ya eran lejanos sus años de juventud, porque esto confirmaría que el poeta está utilizando recuerdos de viajes, no siempre necesariamente reales, para reutilizarlos poéticamente en el marco del mundo de la caballería para el que fueron escritos, ya sea, en este caso, para decirnos lo que no debe hacer un caballero, o para referirse, siguiendo a A. Schwob (véase la nota 31 ), a su prisión en

puntuación- con los anteriores y no con los siguientes, lo que nos permite seguir insistiendo en nuestra interpretación de que su inmovilidad física y vital habria sido consecuencia directa de su estancia en la corte del Rey Rojo y no de su posterior estancia en prisión. Además, el sufrimiento que irradia el poema puede ser interpretado también como inherente a la vida del caballero que fue Wolkenstein, y, en este sentido, el contraste entre las dos primeras estrofas y el resto del poema no tiene que ser considerado necesariamente como tal. Quizás una futura fijación de la puntuación podría aportar una solución definitiva a la interpretación de esos dos versos finales, pero, de momento, nos ratificamos en la ya expresada arriba. 
Wasserburg, vivencia que, al fin y al cabo, también era consustancial a la vida de los caballeros.

Diremos, pues, para concluir, que, en nuestra opinión, las referencias hechas por Wolkenstein en sus poemas a España y a sus distintos reinos, así como a otros lugares, independientemente de que respondan o no a viajes efectivamente realizados, son utilizados en su poemas para destacar el lado viajero y aventurero de todo caballero y para enmarcar, puesto que siempre suelen aparecer al principio de los mismos, el resto de experiencias vitales propias de su oficio: el servicio a nobles damas y la defensa del mundo cristiano, y que se aderezan con las múltiples prisiones, miserias y alegrías propias de ese tipo de vida. No sabemos si el trovador visitó o no al Rey Bermejo en su corte de Granada, y es posible que nunca lo sepamos, pero lo que sí es casi seguro es que ni ejerció en las moras la fascinación que Beda Weber describe, ni aprendió el árabe ni las canciones con las que luego maravilló a sus compatriotas alemanes a su vuelta de tierras granadinas, escenas que sólo un romántico, como lo era el citado crítico, pudo imaginar en su mente para luego hacerles formar parte de la vida del último trovador alemán, de la figura mítica que él creó en su biografía. Pero en sus palabras, en sus versos, sólo leemos lo que él y otras figuras poéticas de esa época hicieron: describir las hazañas y aventuras de un caballero. 


\section{BIBLIOGRAFÍA}

- Baasch, K. y Nürnberg, H., Oswald von Wolkenstein, Reinbeck bei Hamburg, 1986.

- Feldges, Mathias, "In Katlon und Ispanien, do man gern ist kestanien", en: Zeitschrift für deutsche Philologie, 95 (1976), pp. 374-399.

- Golther, Wolfgang, Die deutsche Dichtung im Mittelalter. 800 bis 1500, Stuttgart, 1912.

- Klein, Kurt, Die Lieder Oswalds von Wolkenstein, Tübingen, 1962.

- Mann, Otto, "Oswald von Wolkenstein und die Fremde", Beiträge zur neueren Literaturgeschichte, 16 (1930), pp. 44-57.

- Mayr, Norbert, Die Reiselieder und Reisen Oswalds von Wolkenstein, Innsbruck, 1961.

- Robertshaw, A., Oswald von Wolkenstein, the myth and the man, Göppingen, 1977.

- Rüll, Walter, Oswald von Wolkenstein, Darmstadt, 1981.

- Schack, Adolf Friedrich von, Poesta y arte de los arabes en España y Sicilia, Berlin, 1865; trad. esp. de Juan Valera, Sevilla, 1881; reimpr. Madrid, 1988.

- Schwob, Anton, "Historische Realität und literarische Umsetzung. Beobachtungen zur Stilisierung der Gefangenschaft in den Liedern Oswalds von Wolkenstein", en: Innsbrucker Beiträge zur Kulturwissenschaft, 9 (1979), pp. 161-134.

- Spitzer, Leo, "Romanisches bei Oswald von Wolkenstein", en: Neuphilologische Mitteilungen, 21 (1920), pp. 74-77.

- Wachinger, Burghart, Oswald von Wolkenstein. Eine Auswahl aus seinen Liedern, Ebenhausen bei München, 1964.

- Wehrli, Max, Geschichte der deutschen Literatur von den Anfangen bis zur Gegenwart, Tomo I, Stuttgart, 1984. 